\title{
The GH/IGF-1-Axis in Psychopathological Functions
}

\author{
M. Auer ${ }^{*}$, C. Sievers ${ }^{\S}$, H.J. Schneider and G.K. Stalla
}

Max Planck Institute of Psychiatry, Munich, Germany

\begin{abstract}
Alterations of the somatotropic system as seen in Growth Hormone Deficiency (GHD) or acromegaly can lead to a variety of mental and physical impairments. Especially the prevalence of psychiatric disorders is elevated and cognitive function is impaired. These changes are paralleled by disturbances of the macroscopic brain tissue architecture and may persist despite achievement of biochemical control. On the other hand strong alterations in GH-secretion and impaired regulatory response to exogenous stimulation have been described in a variety of studies investigating the somatotropic feedback-loop in mood disorders. This reciprocal relationship indicates certain effects of this hormone system in the modulation of neuronal function and an involvement in the pathogenesis of psychiatric disorders.
\end{abstract}

Keywords: Acromegaly, affective disorders, anxiety, depression, growth hormone deficiency, IGF-1, mood.

\section{INTRODUCTION}

The presence of growth hormone $(\mathrm{GH})$ and insulin-like growth factor 1 (IGF-1) receptors in many areas of the brain, the fact that both hormones are produced in the brain and the strong evidence that both, GH and IGF-1 may pass the blood-brain barrier suggest relevant clinical effects of the somatotropic system on the central nervous system [1]. In humans, deficiency of GH secretion and low IGF-1 levels as well as overexpression of these hormones may cause typical changes in brain function. On the other hand, there is also evidence for the opposite causality: alterations of brain function such as in affective disorders can lead to changes in GH and/or IGF-1 secretion. The classical reasons for GH deficiency are intrapituitary masses such as pituitary adenomas. In addition to that, brain damage such as traumatic brain injury or subarachnoid haemorrhage may be a common cause of hypopituitarism and GH deficiency in 10 to $20 \%$ of all affected patients [2]. In these cases, it is however difficult to clinically distinguish whether brain injury, GH deficiency, or both cause the frequently observed brain dysfunctions including a negative impact on mental health and patients' quality of life. Further it is not clear whether GH substitution improves these alterations as clinical intervention studies in this field are sparse. A model to study the opposite direction of effects on the brain, being GH and IGF-1 excess, represents the disease acromegaly in humans. In acromegaly, patients show a distinct pattern of increased anxiety-related personality traits [3]. Additionally, the prevalence of psychiatric disorders is elevated and cognitive function is impaired [3,4]. These changes are paralleled by disturbances of the macroscopic brain tissue architecture [5].

*Address correspondence to this author at the Max Planck Institute of Psychiatry, Kraepelinstr. 2-10, D-80804 Munich, Germany; Tel: +49-8930622-364; E-mail: mauer@mpipsykl.mpg.de

${ }^{\S}$ Equal contribution.
The following review will start with an overview about the role of the GH/IGF-1 system in psychiatric disorders in animal models. It will then focus on the effects of GH/IGF-1 alterations and mental health in models of human diseases such as affective disorders, GH deficiency and acromegaly.

\section{THE GH/IGF-1 AXIS AND PSYCHOPATHOLOGY IN ANIMAL MODELS}

\section{Anxiety}

Several studies, investigating central actions of the somatotropic system have been focusing on the characteristics of the GH mediator IGF-1 instead of GH itself. In animal models, systemic administration of IGF-1 was found to induce neuronal activity, expression of genes, neuroplasticity, and neurogenesis, especially in the proliferative areas of the subgranular zone of the dentate gyrus of the hippocampus and the subventricular zone [6-8]. Interestingly, especially the latter brain region might provide a possible causal explanation how the GH-system may exert its central effects on mood, not only by transient modifications but also by permanent changes in the neuronal environment of the brain. Though translation of results obtained by psychiatric animal models into man contains several limitations, there is also evidence for a positive correlation of trait anxiety with the hippocampal volume in humans [9]. However, there are also reports contradicting a connection of hippocampal volume with trait anxiety [10].

In line with these findings, mice-models have been established trying to provide a causal link between exercise, IGF-1, neurogenesis and anxiety-like behaviour (Fig. 1). Trejo et al. [11] first demonstrated that the IGF-1 uptake to the brain is increased by physical exercise in a rat model. IGF-1 uptake is followed by an increase of Brain-derived neurotrophic factor (BDNF) and the consecutive formation of new neurons in the dentate gyrus of the hippocampus in their experiments. In addition to these findings, exercise was shown to induce anxiolytic effects, which could be blocked 


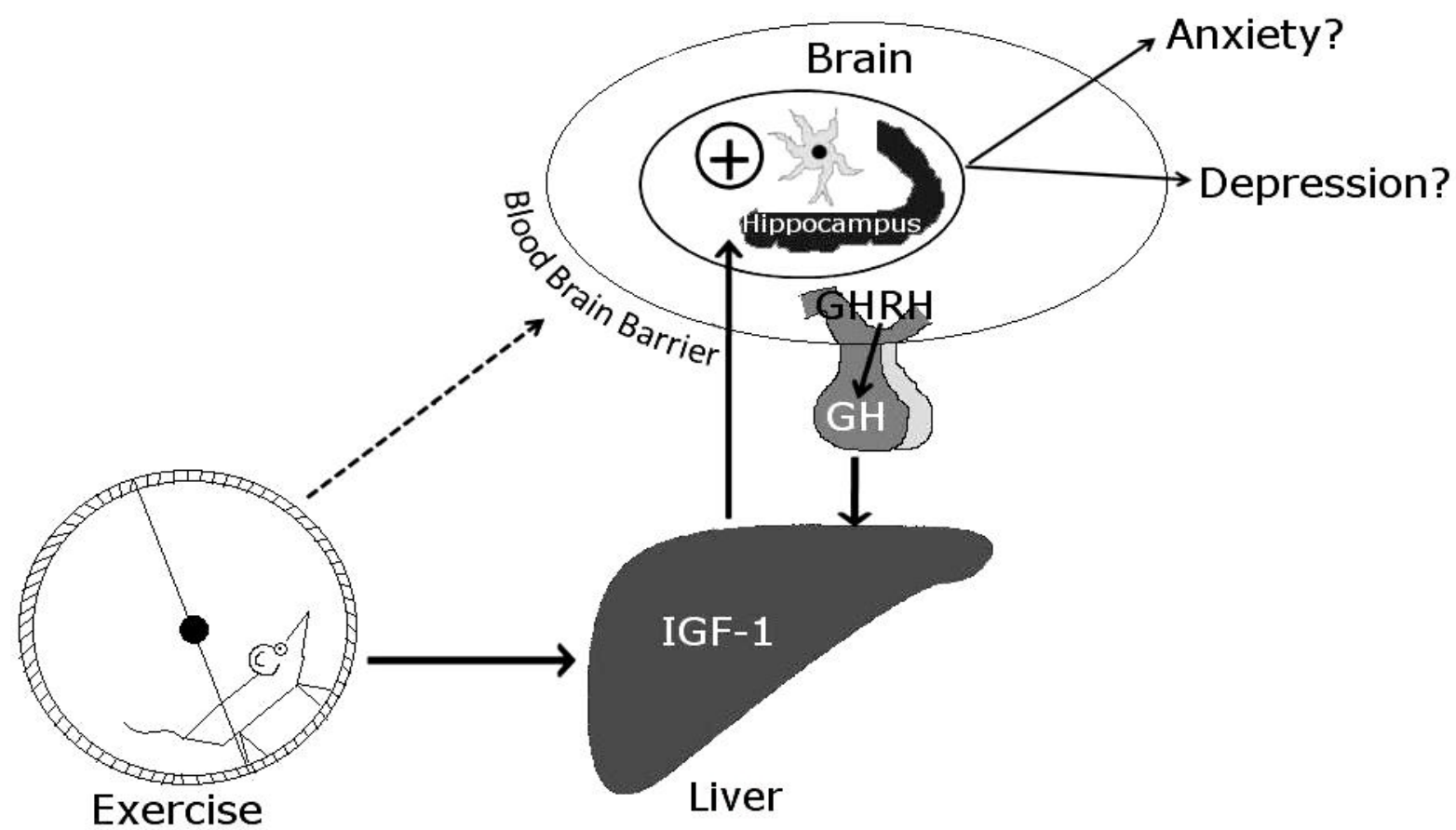

Fig. (1). Exercise induced and IGF-1 mediated changes in brain architecture and mood. Apart from an endogenous expression of IGF-1 in the brain, plasma IGF-1 may pass the Blood Brain Barrier by active and passive transport mechanisms. Regarding animal models, IGF-1 uptake to the brain has been demonstrated to be increased by physical exercise due to transient modifications of the Blood Brain Barrier. This was then followed by the formation of new neurons in the dentate gyrus of the hippocampus. There are several studies reporting a strong association of altered hippocampal neurogenesis with affective disorders such as anxiety and depression. Though evidence in humans is still lacking this might provide a possible explanation for persistent mood impairments in GH-related diseases.

by the administration of anti-IGF-1-antibodies. Additionally, exercise-induced IGF-1 mediated neurogenesis in the hippocampus, though these effects seemed to be highly dependent on the state of differentiation of the new born cells [12]. On the other hand, mice lacking IGF-1 production in the liver investigated in another study did not display these anxiolytic effects after exercise [13], implicating that peripheral IGF-1 which enters the brain, may be more important for behaviour control than the endogenous production in the brain.

Though not investigating direct IGF-1 influences, there have been recent reports on increased neurogenesis and levels of BDNF in the dentate gyrus of the hippocampus induced by voluntarily exercise in mice, leading to a pronounced anxiety-like behaviour [14]. Reduction of hippocampal neurogenesis by irradiation did not alter hippocampal BDNF levels but still lead to a significant reduction of anxiety-like behaviour in the examined mice population [15]. In another mouse model, mice with higher amount of surviving new neurons displayed a behavioural pattern characterized by social avoidance [16]. In a rat model, lesions in specific regions of the hippocampus like the ventral zone were shown to be associated with a reduced anxious phenotype [17].

In general, there seems to be the rule that exceptionally high as well as markedly reduced numbers of new born cells and their impaired integration into the hippocampal circuit is associated with an increased anxiety-like behaviour $[15,18$,
19]. Speculatively speaking if a balanced level of neurogenesis in the hippocampus is one of the various elements in anxiety control this might provide helpful information on the clinical observation that anxious phenotypes may appear in patients with GH-excess as well as in those suffering from deficiency.

Another interesting observation in this context has been made by the injection of somatostatin, one of the major modulators of GH-secretion, into the cerebroventricular system. By doing so, anxiolytic and antidepressant effects have been induced which seemed to be mediated through changes in the neuronal activity in the hippocampus. Nevertheless, these effects have been primarily ascribed to somatostatin's function as a neurotransmitter and its binding capacity to specific somatostatin receptors in the brain rather than to its function in somatotropic suppression $[20,21]$.

\section{Depression}

Depression-like mood alterations are frequently observed in GH-deficient individuals [3, 22, 23].

In mouse models a reduction of peripheral and central IGF-1 in the hippocampus led to a depression-like behavioural pattern, pointing out once more that both sources of this mediator are eliciting effects in the central nervous [24].

Again, the hippocampal neurogenesis is considered to have an impact on major depression as well. It must be 
recognized, that neurogenesis especially in the hippocampus has been speculated to be associated with the therapeutical effect of anti-depressant drugs, since these effects could be blocked by neurogenesis inhibition. However, it remains unclear if increase of neurogenesis per se may have positive effects on depression-like behaviours $[25,26]$.

Again, it has been reported that exercise elicits beneficial effect in depressive patients [27]. It has also been demonstrated to promote neurogenesis in the hippocampus in a mouse model [28]. These effects could at least partly be attributed to modifications by the GH/IGF-1-system as chronic IGF-1 treatment in mice exerts antidepressant effects and the administration of anti-IGF-1 antibodies resulted in the abolishment of exercise-induced antidepressant effects [29]. In another study an increase in free serum IGF-1, performed by the administration of an IGF-binding protein inhibitor, resulted in anxiolytic and antidepressant improvements which consecutively could be reversed by the administration of an IGF-1 receptor antagonist [30].

In contrast to the results described above, indicating that IGF-1 is a major player in antagonising depression-like behaviour, it has been demonstrated that the upstream regulatory elements as GH and GHRH may be equally relevant in this context. A study in mice revealed that exogenous administration of the GHRH-antagonist MZ-4-71 resulted in an in accentuated depressive phenotype [31].

In view of the complexity of the brain, basing upon the interplay of myriads of neurons and their synapses it should be emphasized that observations on the number of new-born cells should be interpreted with caution and only in the context of the awareness of its limitations. Little is known about the existence of neurogenesis in humans, not to mention its potential functional relevance, and a sole increase in neurons must not be equalized with an increased complexity of neuronal circuits. Even by acknowledging its functional role in the process of neuronal adaption, one should refrain from regarding the sole appearance of newborn cells as exclusively beneficial or harmful.

Without going into detail, psychiatric illnesses are beyond doubt highly complex brain disorder, presenting with multiple symptoms and disturbances, reflecting dysfunctions on various levels of the brain.

It should also be stressed in this context that the value of animal models itself simulating psychiatric conditions in humans is subject of controversial debate [32, 33].

Considering the fundamental differences in brain architecture and behavioural demands between humans and animals, results generated by these models should therefore be cautiously interpreted.

\section{ALTERATIONS OF THE SOMATOTROPIC SYSTEM IN PATIENTS WITH PSYCHOPATHOLOGICAL FUNCTION}

Strong alterations in GH-secretion and impaired regulatory response to exogenous stimulation have been described in a variety of studies investigating the somatotropic feedback-loop in mood and anxiety disorders. However, a causal relationship remains unclear.

Whereas healthy individuals show a significant GH increase after physical exercise, young men with high scores of depression and anxiety present with a reduced or no increase in $\mathrm{GH}$ secretion subsequent to physical activity [34]. Comparable results were obtained in a study in mainly female patients, showing a blunted GH response following physical activity [35]. Other investigators found a reduced 24-h GH secretion in depressive patients mainly attributed to decreased nocturnal GH levels [36, 37]. This has been confirmed in another study measuring only nocturnal GH secretion [38]. However, these results were challenged by others reporting unchanged daytime GH secretion [39] or even increased 24-h GH secretion due to elevated diurnal levels $[40,41]$. Regarding stimulation testing in depressive patients, it has been shown that GH response to GHRH [38] and clonidine [42] is reduced though elevated levels of IGF1 have been observed [39, 43].

In children with depressive symptoms, $\mathrm{GH}$ response to insulin induced hypoglycaemia [44] and to the administration GHRH [45] is decreased.

It is noteworthy that not only children and adolescents suffering from clinical depression but also those, who are at a high risk for developing such as disease due to a positive family history present with a reduced increase of GH to GHRH stimulation testing [46].

It should be kept in mind that for example patients suffering from major depression, display a variety of hormonal alterations especially in regard to disturbances of the hypothalamic-pituitary-adrenal axis (HPA) [47]. Since virtually every hormone-axis is interacting with another in some way, it is sometimes difficult to discriminate between the different effects exerted by the individual hormones. [48, 49]

\section{PSYCHOPATHOLOGICAL FUNCTION IN PATIENTS WITH GH DEFICIENCY}

A study suggested a high prevalence of social phobia in adults with early GH-deficiency though they were treated with GH during childhood [50]. This anxious phenotype could not only be ascribed to a short statue due to GHD and consecutive difficulties in social interactions, since a comparison group with growth hormone-independent short statue did not represent with social phobia [51]. One study revealed an impaired quality of life and depressive characteristics in patients presenting with GH-deficiency after treatment for acromegaly compared to their GH-stable controls [52]. Adults with Childhood Onset Growth Hormone Deficiency (CoGHD) who were treated with GH during childhood had similar school achievements as their peers, but were more likely to be unemployed or underemployed and were often unmarried. Depression, particularly anxiety disorders and social phobia, was observed in these patients as well $[53,54]$.

It has been found that patients with Adult onset growth hormone deficiency (AoGHD) have more difficulties in working and reduced enjoyment from social occasions than 
patients with CoGHD $[55,56]$. This has been attributed to the fact that CoGHD patients grow up with the problems associated with GHD, whereas patients with AoGHD are aware of the difference between before and after the development of GHD. Another study showed a high prevalence of atypical depression in AoGHD patients who would benefit from a substitution therapy in terms of less pronounced depressive behavioural patters. In addition to that improvements energy levels and less sleep disturbance was documented [22]. Pointing in the same direction, a recent study reported beneficial effects of GH-substitution on depressive tendencies in GH-deficient children, suggesting a causal relationship [23]. In line with these findings the administration of $\mathrm{GH}$ had a positive impact on depressive behavioural patterns of a small study population consisting of 6 individuals, which from GH- deficiency due to major head trauma [57].

\section{PSYCHOPATHOLOGICAL PATIENTS WITH GH EXCESS}

FUNCTION IN

Interestingly not only lower levels of $\mathrm{GH}$ but also excessive GH- release as in acromegaly may result in distinct mood alterations, though there are only few studies investigating the characteristic features of $\mathrm{GH}$ excess on psychiatric malfunctions $[3,4,58-61]$. A cross sectional study on 81 acromegalic patients showed an elevated risk for major depression and dysthymia, while panic disorders were less prevalent compared to two control groups of subjects with and without other chronic somatic disorders [4].

Even biochemical control achieved by either surgery, radiotherapy, radiosurgery or medical therapy usually improves most of the somatic comorbidities [62, 63], but often fails to restore full quality of life and mental health [3, $4,61,64,65]$. These permanent impairments might be due to irreversible neuronal changes in the presence of long-term GH-IGF-1 excess. Though in vivo studies on this topic are sparse, there has been on study on 44 acromegalic patients, revealing that these patients exhibited larger GM and WM volumes while CSF was reduced [5]. In addition to that, a recent study by Sievers et al. revealed an increased hippocampal volume in acromegalic patients particularly early in the disease course [66].

\section{CONCLUSION}

Alterations of the somatotropic system can lead to a variety of mental and physical impairments due to its diverse functions in neuronal development and its regulatory effects on brain function.

Taken together, most studies on affective disorders report a disturbance of $\mathrm{GH}$ secretion. Even though data are somewhat conflicting, evidence points toward a blunted GH response after stimulation in depressed patients. As this has also been observed in non-depressed family members of depressive patients, it is possible that blunted GH secretion may be a trait marker for subjects at high risk for depression. On the other hand GHD as well as acromegaly may lead to severe alterations in mood control indicating a contribution of a balanced GH-system to a functional integrity of certain brain circuits which might be impaired in psychiatric malfunction. It has to be noted, that these impairments might not vanish despite biochemical disease control or adequate hormonal substitution. In line with these observations, there is evidence that the GHRH-GH-IGF-1-axis may exert permanent changes in brain architecture. Especially the hippocampus, a brain region which is widely associated with various mental dysfunctions such as depression and anxiety related traits, appears to play a certain role in this context. The complex mechanisms underlying these interrelations are, however, still to be clarified.

\section{CONFLICT OF INTEREST}

The authors confirm that this article content has no conflict of interest.

\section{ACKNOWLEDGEMENT}

Declared none.

\section{REFERENCES}

[1] Schneider HJ, Pagotto U, Stalla GK. Central effects of the somatotropic system. Eur J Endocrinol 2003; 149: 377-92.

[2] Schneider HJ, Kreitschmann-Andermahr I, Ghigo E, Stalla GK, Agha A. Hypothalamopituitary dysfunction following traumatic brain injury and aneurysmal subarachnoid hemorrhage: a systematic review. JAMA 2007; 298: 1429-38.

[3] Sievers C, Ising M, Pfister H, et al. Personality in patients with pituitary adenomas is characterized by increased anxiety-related traits: comparison of 70 acromegalic patients with patients with non-functioning pituitary adenomas and age- and gender-matched controls. Eur J Endocrinol 2009; 160: 367-73.

[4] Sievers C, Dimopoulou C, Pfister H, et al. Prevalence of mental disorders in acromegaly: a cross-sectional study in 81 acromegalic patients. Clin Endocrinol (Oxf) 2009; 71: 691-701.

[5] Sievers C, Samann PG, Dose T, et al. Macroscopic brain architecture changes and white matter pathology in acromegaly: a clinicoradiological study. Pituitary 2009; 12: 177-85.

[6] Trejo JL, Carro E, Garcia-Galloway E, Torres-Aleman I. Role of insulin-like growth factor I signaling in neurodegenerative diseases. J Mol Med 2004; 82: 156-62.

[7] Carro E, Trejo JL, Nunez A, Torres-Aleman I. Brain repair and neuroprotection by serum insulin-like growth factor I. Mol Neurobiol 2003; 27: 153-62.

[8] Aberg ND, Brywe KG, Isgaard J. Aspects of growth hormone and insulin-like growth factor-I related to neuroprotection, regeneration, and functional plasticity in the adult brain. ScientificWorldJournal 2006; 6: 53-80.

[9] Rusch BD, Abercrombie HC, Oakes TR, Schaefer SM, Davidson RJ. Hippocampal morphometry in depressed patients and control subjects: relations to anxiety symptoms. Biol Psychiatry 2001; 50: 960-64.

[10] Woollett K, Glensman J, Maguire EA. Non-spatial expertise and hippocampal gray matter volume in humans. Hippocampus 2008; 18: 981-84.

[11] Trejo JL, Carro E, Torres-Aleman I. Circulating insulin-like growth factor I mediates exercise-induced increases in the number of new neurons in the adult hippocampus. J Neurosci 2001; 21: 1628-34.

[12] Llorens-Martin M, Torres-Aleman I, Trejo JL. Exercise modulates insulin-like growth factor 1-dependent and -independent effects on adult hippocampal neurogenesis and behaviour. Mol Cell Neurosci 2010; 44: 109-17.

[13] Trejo JL, Llorens-Martin MV, Torres-Aleman I. The effects of exercise on spatial learning and anxiety-like behavior are mediated by an IGF-I-dependent mechanism related to hippocampal neurogenesis. Mol Cell Neurosci 2008; 37: 402-11.

[14] Fuss J, Ben Abdallah NM, Vogt MA, et al. Voluntary exercise induces anxiety-like behavior in adult $\mathrm{C} 57 \mathrm{BL} / 6 \mathrm{~J}$ mice correlating with hippocampal neurogenesis. Hippocampus 2010; 20: 364-76.

[15] Fuss J, Ben Abdallah NM, Hensley FW, Weber KJ, Hellweg R, Gass P. Deletion of running-induced hippocampal neurogenesis by 
irradiation prevents development of an anxious phenotype in mice. PLoS One 2010; 5: e12769.

[16] Lagace DC, Donovan $\mathrm{MH}$, DeCarolis NA, et al. Adult hippocampal neurogenesis is functionally important for stressinduced social avoidance. Proc Natl Acad Sci USA 2010; 107: 4436-41.

[17] Bannerman DM, Grubb M, Deacon RM, Yee BK, Feldon J, Rawlins JN. Ventral hippocampal lesions affect anxiety but not spatial learning. Behav Brain Res 2003; 139: 197-213.

[18] Revest JM, Dupret D, Koehl M, et al. Adult hippocampal neurogenesis is involved in anxiety-related behaviors. Mol Psychiatry 2009; 14: 959-67.

[19] Bergami M, Rimondini R, Santi S, Blum R, Gotz M, Canossa M. Deletion of TrkB in adult progenitors alters newborn neuron integration into hippocampal circuits and increases anxiety-like behavior. Proc Natl Acad Sci USA 2008; 105: 15570-5.

[20] Engin E, Stellbrink J, Treit D, Dickson CT. Anxiolytic and antidepressant effects of intracerebroventricularly administered somatostatin: behavioral and neurophysiological evidence. Neuroscience 2008; 157: 666-76.

[21] Engin E, Treit D. Anxiolytic and antidepressant actions of somatostatin: the role of sst2 and sst3 receptors. Psychopharmacology (Berl) 2009; 206: 281-9.

[22] Mahajan T, Crown A, Checkley S, Farmer A, Lightman S. Atypical depression in growth hormone deficient adults, and the beneficial effects of growth hormone treatment on depression and quality of life. Eur J Endocrinol 2004; 151: 325-32.

[23] Abe S, Okumura A, Mukae T, et al. Depressive tendency in children with growth hormone deficiency. J Paediatr Child Health 2009, 45: 636-40.

[24] Mitschelen M, Yan H, Farley JA, et al. Long-term deficiency of circulating and hippocampal insulin-like growth factor I induces depressive behavior in adult mice: a potential model of geriatric depression. Neuroscience 2011; 185: 50-60.

[25] Pollak DD, Monje FJ, Zuckerman L, Denny CA, Drew MR, Kandel ER. An animal model of a behavioral intervention for depression. Neuron 2008; 60: 149-61.

[26] Surget A, Saxe M, Leman S, et al. Drug-dependent requirement of hippocampal neurogenesis in a model of depression and of antidepressant reversal. Biol Psychiatry 2008; 64: 293-301.

[27] Singh NA, Clements KM, Singh MA. The efficacy of exercise as a long-term antidepressant in elderly subjects: a randomized, controlled trial. J Gerontol A Biol Sci Med Sci 2001; 56: M497504.

[28] van Praag H, Shubert T, Zhao C, Gage FH. Exercise enhances learning and hippocampal neurogenesis in aged mice. J Neurosci 2005; 25: 8680-5.

[29] Duman CH, Schlesinger L, Terwilliger R, Russell DS, Newton SS, Duman RS. Peripheral insulin-like growth factor-I produces antidepressant-like behavior and contributes to the effect of exercise. Behav Brain Res 2009; 198: 366-71.

[30] Malberg JE, Platt B, Rizzo SJ, et al. Increasing the levels of insulin-like growth factor-I by an IGF binding protein inhibitor produces anxiolytic and antidepressant-like effects. Neuropsychopharmacology 2007; 32: 2360-8.

[31] Telegdy G, Tanaka M, Schally AV. Effects of the growth hormonereleasing hormone $(\mathrm{GH}-\mathrm{RH})$ antagonist on brain functions in mice. Behav Brain Res 2011; 224: 155-8.

[32] Bourin M, Fiocco AJ, Clenet F. How valuable are animal models in defining antidepressant activity? Hum Psychopharmacol 2001; 16: 9-21.

[33] Matthews K, Christmas D, Swan J, Sorrell E. Animal models of depression: navigating through the clinical fog. Neurosci Biobehav Rev 2005; 29: 503-13.

[34] Harro J, Rimm H, Harro M, Grauberg M, Karelson K, Viru AM. Association of depressiveness with blunted growth hormone response to maximal physical exercise in young healthy men. Psychoneuroendocrinology 1999; 24: 505-17.

[35] Krogh J, Nordentoft M, Mohammad-Nezhad M, Westrin A. Growth hormone, prolactin and cortisol response to exercise in patients with depression. J Affect Disord 2010; 125: 189-97.

[36] Voderholzer U, Laakmann G, Wittmann R, et al. Profiles of spontaneous 24-hour and stimulated growth hormone secretion in male patients with endogenous depression. Psychiatry Res 1993; 47: 215-27.
[37] Fiasche R, Fideleff HL, Moisezowicz J, Frieder P, Pagano SM, Holland M. Growth hormone neurosecretory disfunction in major depressive illness. Psychoneuroendocrinology 1995; 20: 727-33.

[38] Sakkas PN, Soldatos CR, Bergiannaki JD, Paparrigopoulos TJ, Stefanis CN. Growth hormone secretion during sleep in male depressed patients. Prog Neuropsychopharmacol Biol Psychiatry 1998; 22: 467-83.

[39] Deuschle M, Blum WF, Strasburger CJ, et al. Insulin-like growth factor-I (IGF-I) plasma concentrations are increased in depressed patients. Psychoneuroendocrinology 1997; 22: 493-503.

[40] Linkowski P, Mendlewicz J, Kerkhofs M, et al. 24-hour profiles of adrenocorticotropin, cortisol, and growth hormone in major depressive illness: effect of antidepressant treatment. J Clin Endocrinol Metab 1987; 65: 141-52.

[41] Mendlewicz J, Linkowski P, Kerkhofs M, et al. Diurnal hypersecretion of growth hormone in depression. J Clin Endocrinol Metab 1985; 60 :505-12.

[42] Mokrani M, Duval F, Diep TS, Bailey PE, Macher JP. Multihormonal responses to clonidine in patients with affective and psychotic symptoms. Psychoneuroendocrinology 2000; 25: 741752.

[43] Franz B, Buysse DJ, Cherry CR, et al. Insulin-like growth factor 1 and growth hormone binding protein in depression: a preliminary communication. J Psychiatr Res 1999; 33: 121-7.

[44] Ryan ND, Dahl RE, Birmaher B, et al. Stimulatory tests of growth hormone secretion in prepubertal major depression: depressed versus normal children. J Am Acad Child Adolesc Psychiatry 1994; 33: 824-33.

[45] Dahl RE, Birmaher B, Williamson DE, et al. Low growth hormone response to growth hormone-releasing hormone in child depression. Biol Psychiatry 2000; 48: 981-8.

[46] Birmaher B, Dahl RE, Williamson DE, et al. Growth hormone secretion in children and adolescents at high risk for major depressive disorder. Arch Gen Psychiatry 2000; 57: 867-72.

[47] Holsboer F, Von Bardeleben U, Gerken A, Stalla GK, Muller OA. Blunted corticotropin and normal cortisol response to human corticotropin-releasing factor in depression. N Engl J Med 1984; 311:27.

[48] Toogood AA, Taylor NF, Shalet SM, Monson JP. Modulation of cortisol metabolism by low-dose growth hormone replacement in elderly hypopituitary patients. J Clin Endocrinol Metab 2000; 85: 1727-30.

[49] Friess E, Bardeleben U, Wiedemann K, Lauer CJ, Holsboer F. Effects of pulsatile cortisol infusion on sleep-EEG and nocturnal growth hormone release in healthy men. J Sleep Res 1994; 3: 73-9.

[50] Stabler B, Tancer ME, Ranc J, Underwood LE. Evidence for social phobia and other psychiatric disorders in adults who were growth hormone deficient during childhood. Anxiety 1996; 2: 86-9.

[51] Nicholas LM, Tancer ME, Silva SG, Underwood LE, Stabler B. Short stature, growth hormone deficiency, and social anxiety. Psychosom Med 1997; 59: 372-5.

[52] Wexler T, Gunnell L, Omer Z, et al. Growth hormone deficiency is associated with decreased quality of life in patients with prior acromegaly. J Clin Endocrinol Metab 2009; 94: 2471-7.

[53] Deijen JB, de Boer H, van der Veen EA. Cognitive changes during growth hormone replacement in adult men. Psychoneuroendocrinology $1998 ; 23: 45-55$.

[54] Stabler B. Impact of growth hormone (GH) therapy on quality of life along the lifespan of GH-treated patients. Horm Res 2001; 56 (Suppl 1): 55-58.

[55] Attanasio AF, Lamberts SW, Matranga AM, et al. Adult growth hormone $(\mathrm{GH})$-deficient patients demonstrate heterogeneity between childhood onset and adult onset before and during human GH treatment. Adult Growth Hormone Deficiency Study Group. J Clin Endocrinol Metab 1997; 82: 82-8.

[56] Hunt SM, McKenna SP, Doward LC. Preliminary report on the development of a disease-specific instrument for assessing quality of life of adults with growth hormone deficiency. Acta Endocrinol (Copenh) 1993; 128 (Suppl 2): 37-40.

[57] Maric NP, Doknic M, Pavlovic D, et al. Psychiatric and neuropsychological changes in growth hormone-deficient patients after traumatic brain injury in response to growth hormone therapy. J Endocrinol Invest 2010; 33: 770-5. 
[58] Ezzat S, Forster MJ, Berchtold P, Redelmeier DA, Boerlin V, Harris AG. Acromegaly. Clinical and biochemical features in 500 patients. Medicine (Baltimore) 1994; 73: 233-40.

[59] Korali Z, Wittchen HU, Pfister H, Hofler M, Oefelein W, Stalla GK. Are patients with pituitary adenomas at an increased risk of mental disorders? Acta Psychiatr Scand 2003; 107: 60-8.

[60] Richert S, Strauss A, Fahlbusch R, Oeckler R, von Werder K. Psychopathologic symptoms and personality traits in patients with florid acromegaly. Schweiz Arch Neurol Psychiatr 1987; 138: 6186.

[61] Rowles SV, Prieto L, Badia X, Shalet SM, Webb SM, Trainer PJ. Quality of life (QOL) in patients with acromegaly is severely impaired: use of a novel measure of QOL: acromegaly quality of life questionnaire. J Clin Endocrinol Metab 2005; 90: 337-41.
[62] Giustina A, Barkan A, Casanueva FF, et al. Citeria for cure of acromegaly: a consensus statement. J Clin Endocrinol Metab 2000; 85: 526-9.

[63] Melmed S, Casanueva FF, Cavagnini F, et al. Guidelines for acromegaly management. J Clin Endocrinol Metab 2002; 87: 4054-8.

[64] Biermasz NR, van Thiel SW, Pereira AM, et al. Decreased quality of life in patients with acromegaly despite long-term cure of growth hormone excess. J Clin Endocrinol Metab 2004; 89: 5369-76.

[65] Bonapart IE, van Domburg R, ten Have SM, et al. The 'bio-assay' quality of life might be a better marker of disease activity in acromegalic patients than serum total IGF-I concentrations. Eur J Endocrinol 2005; 152: 217-24.

[66] Sievers C, Samann PG, Pfister H, et al. Cognitive function in acromegaly: description and brain volumetric correlates. Pituitary 2011 [Epub ahead of print].

Received: November 7, 2011

(C) Auer et al.; Licensee Bentham Open.

This is an open access article licensed under the terms of the Creative Commons Attribution Non-Commercial License (http://creativecommons.org/licenses/by$\mathrm{nc} / 3.0 /$ ) which permits unrestricted, non-commercial use, distribution and reproduction in any medium, provided the work is properly cited. 